\title{
SUSTAINABILITY OF WATER INVESTMENTS IN WEST AFRICA
}

\author{
LAKHDAR BOUKERROU ${ }^{1}$, FAISSAL R. OUEDRAOGO ${ }^{2} \&$ JOHN STEVE KABORE $^{3}$ \\ ${ }^{1}$ College of Engineering and Computing, Florida International University, USA \\ ${ }^{2}$ Department of Civil and Environmental Engineering, University of South Florida, USA \\ ${ }^{3}$ Save the Children International, Monitoring-Evaluation-Accountability and Learning Advisor, Burkina Faso
}

\begin{abstract}
The objective of this case study was to assess the sustainability of the water investments made by the United States Agency for International Development through the West Africa Water, Sanitation and Hygiene Program (USAID WA-WASH) between 2011 and 2015 in Burkina Faso, Ghana, and Niger. During this period, the Program promoted low-cost water technologies with 376 drinking water points installed or rehabilitated; 8,192 household latrines constructed; 5,855 agricultural producers trained on short-term agricultural sector productivity or food security; 5,657 stakeholders increased their capacity to adapt to the impacts of climate change; 7,198 people trained on mainstreaming gender into their development activities. A tool was developed and used to assess the financial, institutional, environmental, technical, and social aspects of the sustainability of the Program investment included in WASH services. The results presented herein focus on the sustainability of the water investments in these three countries. The approach consisted of identifying the number of communities to be monitored; the number of water infrastructures within the community; meeting with local authorities; organizing focus group discussions; visiting all water points installed by the Program in each community; and collecting data on the functionality of the water points. The monitoring and evaluation team conducted four field visits between January 2016 and December 2017 to 72 communities in Burkina Faso, Ghana, and Niger. A different weight was given to each of the five sustainability areas. Data gathered during each of the visits was statistically analysed. The results showed that the water supply sustainability score was very good in Ghana $(81 \%)$ but somewhat lower in Niger (63\% - management committees not functional and no payment of user fees), and in Burkina Faso ( $55 \%$ - relocation of mechanics and a lack of maintenance). In most cases, the beneficiaries continue to use the information and skills acquired from the training, focus group discussions, and technical assistance provided by the USAID WA-WASH Program and the majority of the water points continue to be functional.
\end{abstract}

Keywords: West Africa, sustainability, water supply, investment, USAID, Florida International University.

\section{INTRODUCTION}

According to the 2017 United Nations Human Development Index (HDI), Burkina Faso and Niger were ranked 183 and 189, respectively, among the countries with the lowest HDI in the world. However, Ghana, ranked 139, is considered a medium HDI index country [1]. Although Ghana is ranked higher compared to Burkina Faso and Niger, all three countries are very similar when it comes to access to water supply, sanitation and hygiene services. In the urban areas of these countries, drinking water is provided by a central public or private agency, the National Water and Sanitation Agency (ONEA in French) in Burkina Faso, the Ghana Water Company Limited (GWCL). and the Niger Water Utility Company (SEEN in French). In rural areas, water provision is handled by small private companies or by the rural communities themselves with the support of international development agencies, non-governmental organizations, etc. Different types of water infrastructures are available to urban and rural dwellers in the three countries where this work was conducted (see Table 1). 
Table 1: Water supply in the study area in 2017. (Source: JMP [2].)

\begin{tabular}{|c|c|c|c|c|c|c|}
\hline \multirow{2}{*}{ Country } & Setting & $\begin{array}{c}\text { Safely } \\
\text { managed }\end{array}$ & $\begin{array}{c}\text { At least } \\
\text { basic }\end{array}$ & $\begin{array}{c}\text { Limited } \\
\text { service }\end{array}$ & $\begin{array}{c}\text { Unimproved } \\
\text { facilities }\end{array}$ & $\begin{array}{c}\text { Surface } \\
\text { water }\end{array}$ \\
\hline & & & \multicolumn{5}{c}{$\%$} \\
\hline \multirow{3}{*}{ Burkina Faso } & Urban & & 79.9 & 15.1 & 4.5 & 0.5 \\
\cline { 2 - 7 } & Rural & & 35.5 & 32.9 & 30.5 & 1.6 \\
\hline \multirow{2}{*}{ Ghana } & Urban & 56.5 & 36.2 & & 2.2 & 0.3 \\
\cline { 2 - 7 } & Rural & 11.5 & 56.1 & 13.1 & 6.2 & 13.2 \\
\hline \multirow{2}{*}{ Niger } & Urban & & 84.3 & 11.4 & 2.3 & 2.0 \\
\cline { 2 - 7 } & Rural & & 43.6 & 15.6 & 36.7 & 4.1 \\
\hline
\end{tabular}

As of 2017, Burkina Faso and Niger showed encouraging signs in the access to at least basic services in urban settings with an access rate of $79.9 \%$ and $84.3 \%$, respectively. However, there remains great disparities between urban and rural areas in these two countries. Ghana urban dwellers have better access to safely managed services than rural populations. While more urban people in Ghana have access to at least basic services $(92.7 \%)$ as compared to Burkina Faso (79.9\%) and Niger (84.3\%). Substantial efforts are still needed in all three countries to bring rural areas to at least a basic service level but more so in Burkina Faso where more than $60 \%$ of the rural population have limited access or worst services.

Sustainability is a concept that has been gaining prominence throughout the scientific and development communities for the past decades. Sustainability is defined by Abrams [3] as "whether or not something continues to work overtime". This definition applied to WASH suggests that the technologies installed in the provision of safe drinking water need to continue to be operational beyond the life of a project/program in order to achieve sustainability. This definition lacks a clear specification of the concept of "overtime" and that is where some controversy of the concept of sustainability in the WASH sector comes from. Overtime it can be the designed physical lifetime of the facilities, the lifetime of the project under which it was installed or even a fixed amount of time. Hodgkin [4] brings some clarification to the time concept of sustainability by specifying that sustainability is achieved when the WASH facilities maintain operation over a long period of time when all external investments form international development agencies such as the United States Agency for International Development (USAID), the World Bank (WB), the African Development Bank (AfDB) etc. are withdrawn. Hodgkin infers that a good starting point for the measurement of sustainability should be the end of funding of the WASH facilities; this begins mostly after the installation of the facility. Although the start of sustainability is identified, the end seems to be ideally infinite according to Schouten and Moriarty [5]. Acknowledging that the infinite time is practically impossible, they explain that communities using the facilities will never revert to a lower service level while allowing for system replacement or upgrade at the end of its natural lifespan.

The concept of sustainability is without any doubt a complex yet vital requirement in the WASH sector; therefore, it is imperative to find ways to quantify it. This will allow the sector actors to include it in the design, the implementation, and the monitoring of WASH services provision. Several studies to have strong correlation with sustainability [6]-[11], have 
identified multiple technical and non-technical factors to assess sustainability. These factors include operational community organizations, the ability of the community to function, maintain facilities and raise adequate user fees for spare parts, and a strong backup support from external parties at the local or district level to solve major breakdowns. Measuring these factors is a challenge but various tools have been developed for that purpose with the most relevant to our study: (1) the Dutch WASH Alliance-Sustainability Monitoring Framework (SMF); (2) the Governance into Functionality Tool (GiFT); and (3) the USAID-Rotary International-Sustainability Index Tool (SIT).

All three tools are similarly structured: (1) questions for each indicator category are developed, administered and graded following a specific scale to each question; (2) the grades are aggregated by category and all categories weighted according to their importance (defined by the tool developer); and (3) all scores are summed for a final grade. Boulenouar et al. [12], provide extensive details on each of these tools. USAID WA-WASH sustainability tool encompasses indicators drawn from the Gender Analysis Snapshot (GAS), GiFT, SMF, and SIT. Most of these indicators were reformulated to meet the Program specific needs. Accordingly, this study aims to assess the sustainability of WASH services provided in Burkina Faso, Ghana, and Niger using the USAID WA-WASH sustainability tool.

\section{METHODOLOGY}

\subsection{Data collection method}

Rural WASH services provision in developing countries, particularly in Burkina Faso, Ghana, and Niger is in major part financed by international agencies and implemented by international by various organizations. For the purpose of this study, the investigated WASH services were implemented in the three countries during Phase I (2011-2015) of the USAID WA-WASH Program. The Program aimed to:

- Support catalytic approaches to accelerate regional access to improved water supply/sanitation services and improved hygiene behaviors.

- Develop and implement improved models for sustainability of rural and sub-urban WASH service delivery that could be replicable throughout West Africa.

- Build synergies among WASH actions and critical USAID/West Africa regional priorities related to food security, climate change, and sustainable resource management.

- Strengthen the regional enabling environment and capacity for WASH to achieve WASH Millennium Development Goals in West Africa

The Program's Phase II (2016-2017) focused on three objectives one of which was essentially the monitoring and evaluation of Phase I activities. Under this objective, 72 communities (32 in Burkina Faso, 20 in Ghana and 20 in Niger) were selected. The Program setup a two-year (2015-2017) assignment to conduct periodic monitoring visits in the selected communities within the three countries. The number of communities visited and the total number of water facilities monitored varied from one country to the other because of the initial number of installed facilities (Table 2). The monitoring and evaluation plan was based on the communities' size and the sites' accessibility. Fifty percent of the total improved water points installed by the Program in the three countries were visited. However, all the water facilities in each of the selected communities were monitored/visited. 
Table 2: Total number of water facilities installed and monitored under the Program.

\begin{tabular}{|l|c|c|c|c|}
\hline & Burkina Faso & Ghana & Niger & Total \\
\hline Water facilities installed & 327 & 28 & 52 & 406 \\
\hline Water facilities monitored & 128 & 28 & 47 & 203 \\
\hline
\end{tabular}

\subsection{Sustainability tool development}

USAID WA-WASH sustainability tool encompasses indicators drawn from GAS, GiFT, SMF, and SIT. Other custom indicators were added by the Program to complement the tool and ensure the coverage of all USAID WA-WASH past water supply activities. The tool administration methodology was set up in sequential steps: (1) identify the number of communities for water supply activities; (2) identify the number of water points in each community; (3) meet with the local authorities to announce the field visit objectives and gather their feedback; (4) organize focus group discussions with community members including village development council members, water user associations, etc.; (5) visit all the water points installed by the Program in each community and collect data on each water point. In addition, the USAID WA-WASH team met with the pump manufacturers, driller teams, masons, etc., to document their sales or service provided after the Program field activities, report challenges encountered, and suggest ideas on how they can improve their performance. A one-day workshop per country was organized with these stakeholders after each of the field visits in order to propose and adopt improvement plans for the low-cost technologies promoted by the Program.

Based on the set of questions a scoring system was developed as follows: (1) determine the sustainability score of each water points (out of a possible 10 points) for the five sustainability areas; (2) compute an average score for each water point; (3) aggregate the scores for each sustainability area to obtain an overall score for that area in each community; (4) compute the sustainability score of each sustainability area for all communities (maximum score equals to the number of communities covered multiplied by 10 points); and (5) compute an average sustainability score for each of the countries. For instance, if the monitoring of the water supply past activities was implemented in 20 communities and the sum of the sustainability scores of all 20 communities is 170, the average sustainability score for water supply is 8.5 points (out of a possible of 10). Using this approach, the sustainability scores can be produced by country, province or community.

The tool comprised 28 specific questions grouped into five sustainability categories as follows:

- Technical Sustainability: The technology or hardware installed continues to function, is maintained, repaired and replaced by beneficiaries and it is not depleting the natural resources on which its functioning depends.

- Environmental Sustainability: The implementation of the approach is integrated with sustainable management of water and waste flows and resources.

- Financial Sustainability: A continuity in the delivery of products and services related to WASH; locally financed and do not depend on external (foreign) subsidies.

- Social Sustainability: The appropriate social conditions and prerequisites are realized and sustained.

- Institutional Sustainability: The WASH service users, authorities, and service providers at the local and the national level are clear on their roles, tasks, and responsibilities. 
The scores from each of the questions were aggregated to constitute the category score and the categories scores are weighted following the SIT tool guidelines for weights and summed for the final sustainability score. Table 3 shows the repartition of sustainability questions per sustainability category as well as the weight used to compute the final score. It should be noted that the financial, social, and institutional sustainability categories account for $75 \%$ of the total water supply sustainability score, therefore they have the greatest impact on the overall sustainability score.

Table 3: Sustainability questions repartition and weight per category for the water infrastructures.

\begin{tabular}{|l|c|c|c|c|c|c|}
\hline \multirow{2}{*}{ Water } & \multicolumn{7}{|c|}{ Number of questions } \\
\cline { 2 - 7 } & Financial & Social & Institutional & Environmental & Technical & Total \\
\hline Water supply & 7 & 5 & 5 & 5 & 6 & 28 \\
\hline Weight (\%) & 35 & 20 & 20 & 15 & 10 & 100 \\
\hline
\end{tabular}

\subsection{Data analysis approach}

- Data cleaning and transformation: The initial data collected form the interviews and the observations made in the field are of the "string" type (words and phrases). In this process, the string data are transformed to the corresponding numeric value. This is a tedious but required step in the data processing and analysis procedure.

- Data exploration and management: In this process descriptive statistics in the form of frequency tables are generated for each variable/question. The goal of this exercise is to compare the actual responses to the questions with respect to all possible choices offered. Missing responses and wrong types of responses were detected and removed from the data set.

- Data summary generation: Data set are used to generate statistical outputs of sustainability levels chronological observation per country. Comparisons are made between different sustainability categories and between countries to determine the underlying reasons for success or failures and the possible solutions to be implemented.

- Interpretation: The final interpretation of the data is a single score per facility on a scale of 1 to 10 where a score of: less than $5.9=$ poor sustainability; between 6 and 6.9 = fair sustainability; between 7 and 8.4 = good sustainability; and between 8.5 and $10=$ very good sustainability.

Four visits where completed during the two-year period (2016-2017) meaning that each facility was visited four times during the monitoring and evaluation period. The sustainability of the water infrastructures was assessed using the sustainability tool developed by the Program as described previously.

\section{RESULTS AND DISCUSSION}

As stated above, the financial, institutional and social sustainability categories have considerable influence on the environmental and technical sustainability categories making them the core categories for the analysis of each of the three countries. 


\subsection{Burkina Faso}

The water supply activities and facilities in Burkina Faso displayed a stable and fairly good sustainability over the period of the monitoring visits. Fig. 1 shows the evolution over time of the sustainability score. The average sustainability score was about $60 \%$. A decline of a three percentage points in the sustainability score is observed from Visit 1 (August 2016) to Visit 2 (January 2016); while in Visit 3 (June 2017) that decline was recovered. However, the last visit showed a decline of nine percentage points in the score.

The observed pattern of the overall sustainability score followed the pattern of the financial sustainability which in this case has an impact on all the other categories except for the technical (Fig. 2). In June 2017, the overall sustainability score increased (64\%) because of the increase of the financial sustainability score due to several factors (existence of funds for repairs, affordable spare parts, etc.). During the four visits the institutional sustainability, which measures the existence of management committees, caretakers, mechanics, etc., kept decreasing. This is explained by the mobility of people involved in the institutional activities as they may move to different areas for personal reasons or productive activities and by the fact that people did not take care of their water facility. Indeed, during the visits, the team noticed the presence of stagnant water around some of the water points. Even with a good technical sustainability score ( 8 out of 10 ), beneficiaries stated that they did not use preventive measures to prevent breakdowns of the rope pumps. Beneficiaries reported frequent pump failures due to breakage of the rope even though institutionally, mechanics where present (high institutional sustainability score). The ropes which does not cost much needs to be replaced from time to time because of usage.

For Burkina Faso, most sustainability scores are characterized by a general drop on Visit 2. However, these scores were higher during Visit 3 except for the institutional score. The financial sustainability remained low across all visits especially in Visit 2 (4 out of 10) due to a lack of funding for the replacement of the ropes, a necessary maintenance item for the continued operation of a good service delivery.

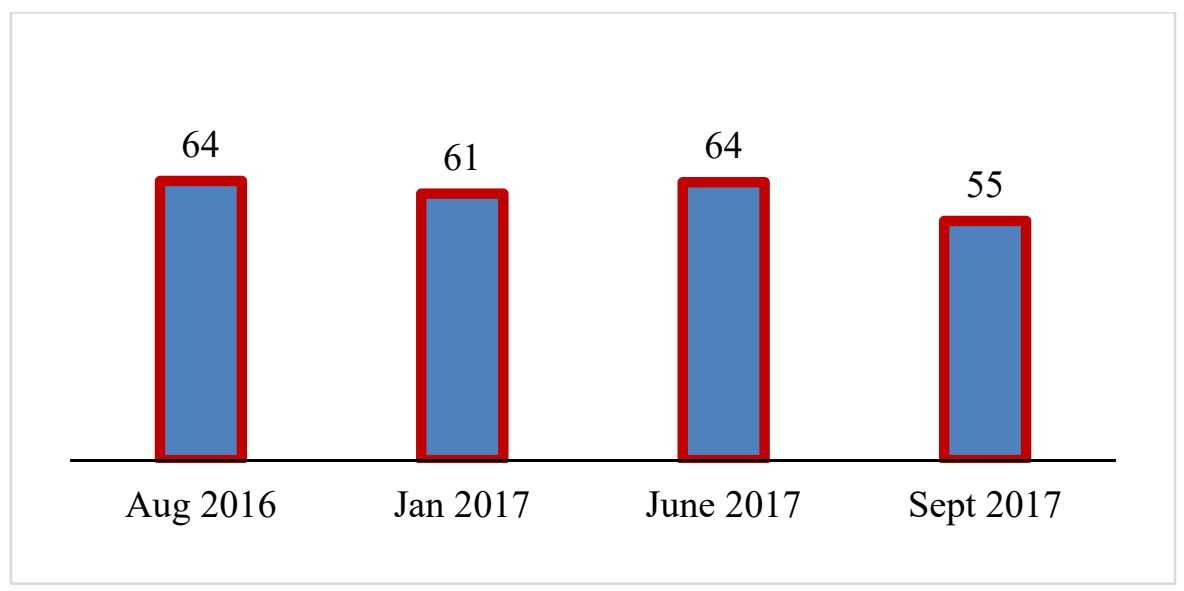

Figure 1: Burkina Faso water supply sustainability score (\%) from August 2016 to September 2017. 


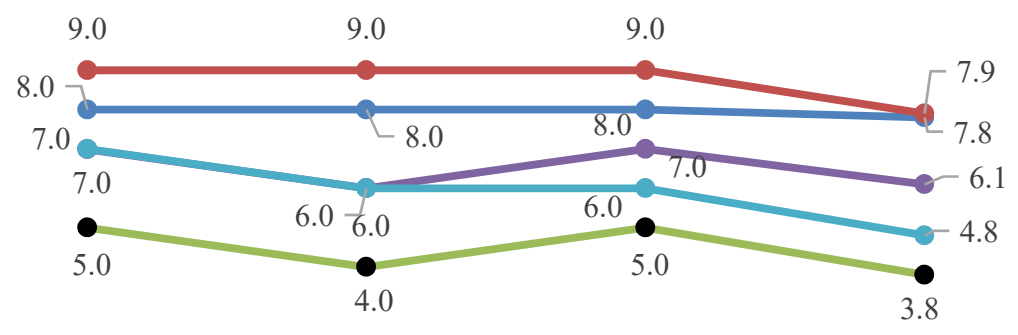

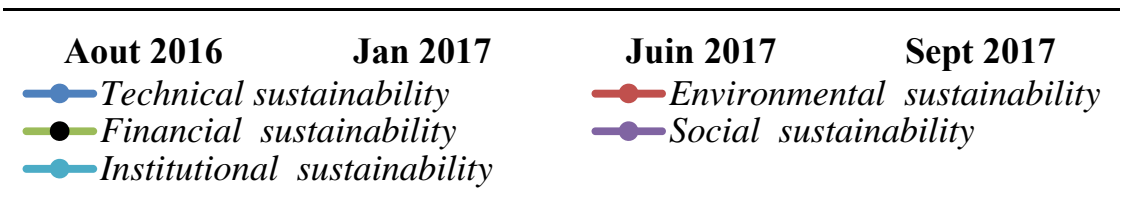

Figure 2: Sustainability category scores (scale 1 to 10) between August 2016 and September 2017 in Burkina Faso.

The highest financial sustainability scores are observed when the social and institutional sustainability factors have simultaneously very high scores. This is due to the fact that $70 \%$ of the sustainability points allocated to the social and institutional sustainability categories are directly related to the beneficiaries been able to have funds when needed for the necessary repairs since the pump is owned by the household. In Burkina Faso, in order to obtain a high financial sustainability score, it is critical that beneficiaries have the funds needed for repairs and do not necessarily rely on outside help for such expenditures.

\subsection{Ghana}

Through the first two field visits, the water supply sustainability score in Ghana remained constant and in the good sustainability range (a point away from the highest sustainability range). The score fell into the fair sustainability range on the third visit as shown in Fig. 3. However, in the fourth visit, Ghana showed the highest score among the three countries.

A slight increase was observed in all sustainability scores from Visit 1 (June 2016) to Visit 2 (November 2016) except for the technical sustainability that experienced a 1-point decrease. In Visit 3 (April 2017), all categories declined except the institutional sustainability which experienced a slight increase. The financial sustainability category experienced the highest decline due to a bad management of the financial records by the water management committee, an issue related to the sharp decline of the social sustainability category. The effect of the social sustainability decline was also felt in the technical sustainability category with a decline in preventive maintenance of the water points.

Overall, the institutional sustainability in Ghana was high and constant for the two year's monitoring period (Fig. 4) mainly because of the availability of caretakers and mechanics. This situation contributed to the good water supply sustainability score. Indeed, the involvement of the caretakers (institutional sustainability) helped in improving the role of women (social sustainability) and cleaning the surroundings of community pumps (environmental sustainability). The sustainability score went up after the third visit because 
more repairs were done, and more water points were functional mostly because beneficiaries had more funds for repairs and maintenance. Also, it should be noted that at the beginning of the rainy season the financial sustainability score was low because resources were allocated to farming operations. Indeed, the beneficiaries underlined the fact that during the rainy season, even though micro credit exists they invest more in agriculture than in the repair and maintenance of the water points. The social and environmental sustainability scores seem to follow the same trend as the financial sustainability score.

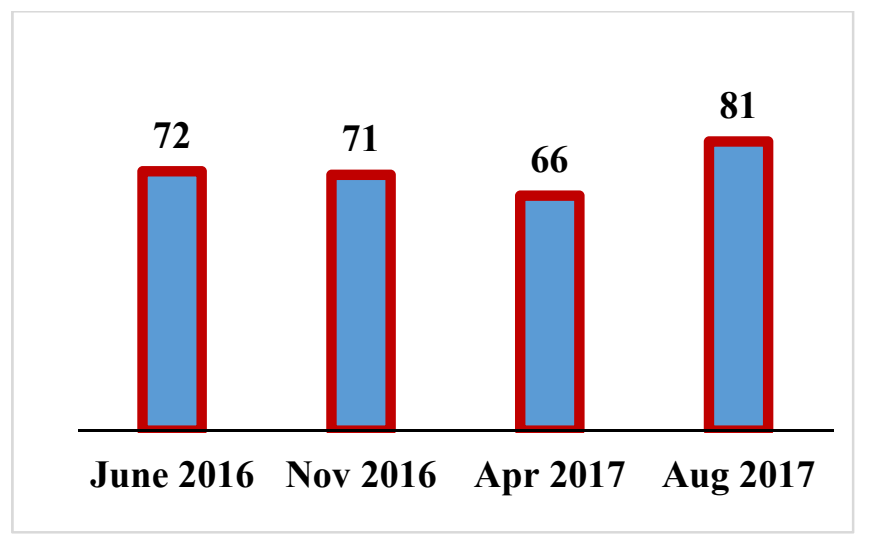

Figure 3: Ghana water supply sustainability score (\%) from June 2016 to August 2017.

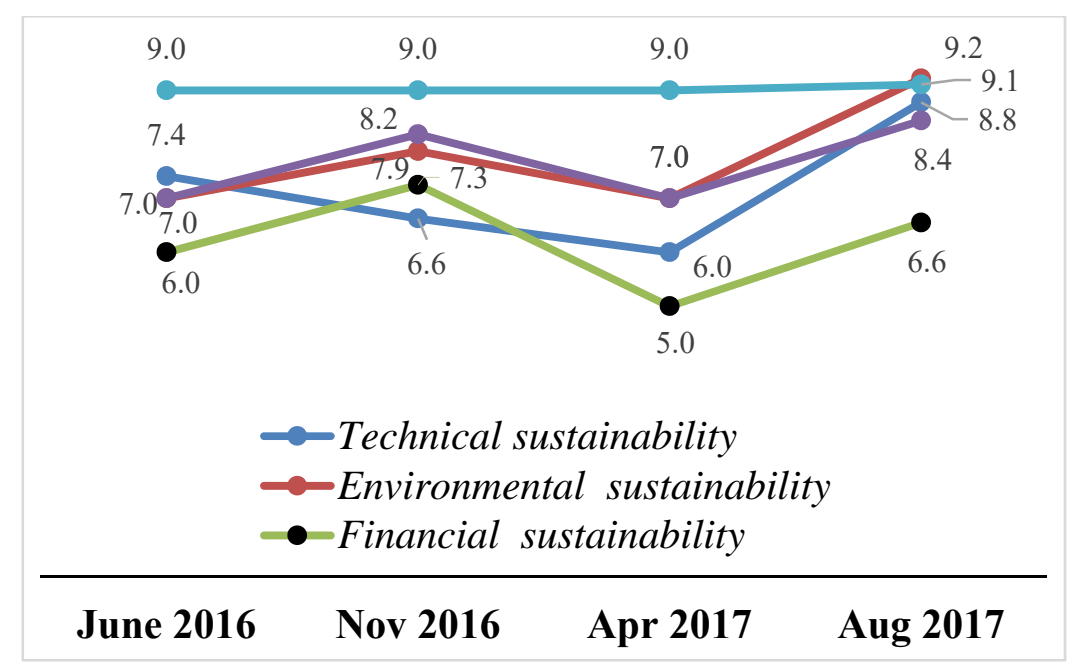

Figure 4: Sustainability scores (scale 1 to 10) between June 2016 to August 2017 in Ghana.

\subsection{Niger}

The overall sustainability score for water supply for Niger remained low across all visits and in the range of poor sustainability (Fig. 5). The sustainability score decreased from May 2016 
(56\%) to September $2016(52 \%)$ because the management committees were no longer functional and therefore this situation contributed to the hindrance of the repairers' activities. However, the score increased from September 2016 (52\%) to July 2017 (63\%) due to the re-establishment of the management committees by the Program team allowing the resumption of the collection of fees for water usage and for the operation and maintenance of the water points. The interventions of the Program team resulted in a score increase for all sustainability areas (Fig. 6).

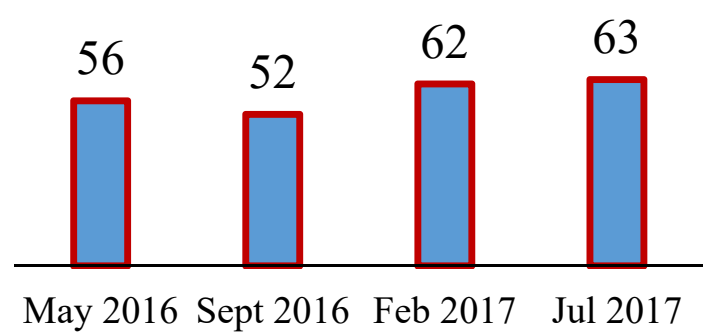

Figure 5: Niger water supply sustainability score (\%) from May 2016 to July 2017.
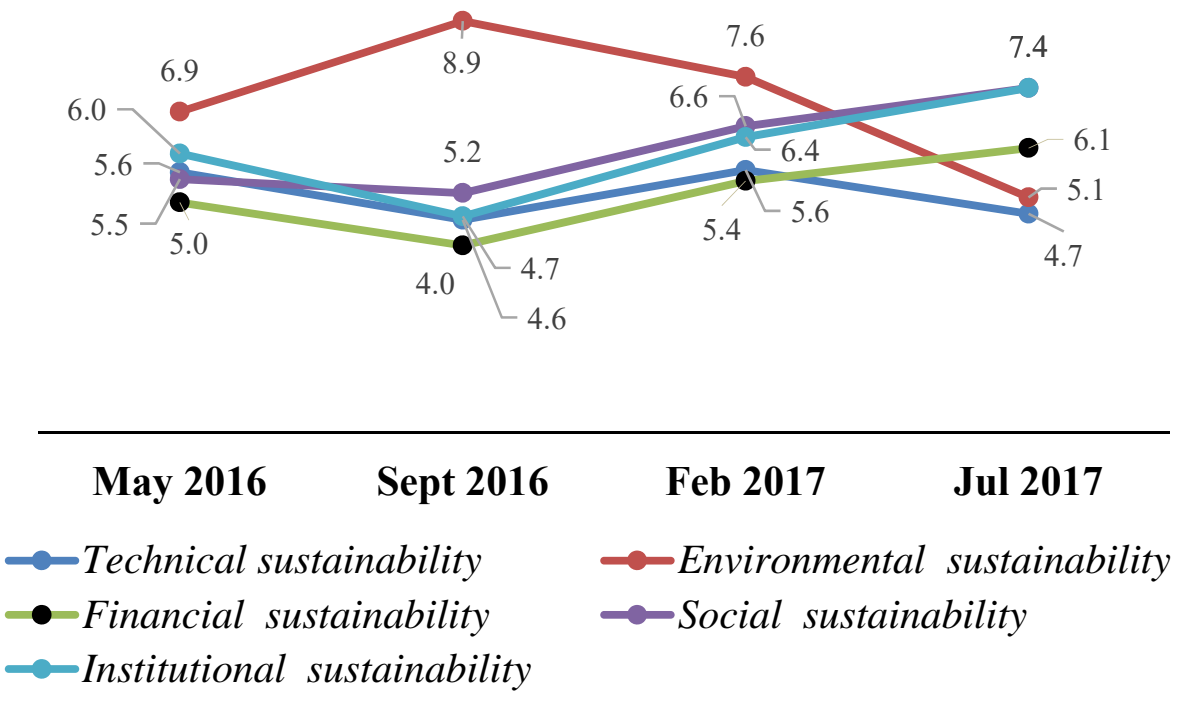

Figure 6: Sustainability scores (scale 1 to 10) between May 2016 to July 2017 in Niger.

The general trend observed in the analysis of the data from Burkina Faso and Ghana is also observed for Niger as well: a high score in social and institutional sustainability creates the conditions for a high financial sustainability score just as the opposite creates a low 
financial sustainability score (Fig. 6). The data also indicated that the low social sustainability score observed in Niger was due in part to the occurrence of conflicts around the water point. As to the questions related to the setup and functionality of a water management committee, the communities scored 0 . This explains the drop in the financial sustainability because when the water management committees are not functional the financial sustainability is more likely to be low regardless of the institutional sustainability score.

Despite the support from the Program, no notable improvements were made between visits suggesting that the beneficiaries did not address the major recommendations made by the Program.

The financial and institutional sustainability areas experienced a decline between Visit 1 (May 2016) and Visit 2 (September 2016). In Visit 3 (February 2017) most of the factors experienced an increase due to more active water management committees and the involvement of women (social sustainability areas). The financial sustainability areas benefitted from the social improvement with a better collection of service delivery and operation and maintenance fees.

\section{CONCLUSION AND RECOMMENDATIONS}

The last sustainability scores observed in the three countries, Burkina Faso 55\%, Ghana $81 \%$ and Niger $63 \%$, indicate that the differences between the countries are substantial. In Burkina Faso, the lack of preventive maintenance contributed to the low overall sustainability score despite the presence of mechanics. In addition, the beneficiaries reported that the spare parts (rope) was not affordable. While the cost of the rope is very low, we believe that people expect financial assistance even for small things. The positive thing about Ghana is that the breakdowns lasted less than three days and the breakdown frequency was less than three breakdowns per quarter. Most of the communities had funds dedicated to the repairs. Also, the water points in Ghana were well maintained, very few water points had livestock around them and or the existence of solid waste - there was no presence of possible sources of contamination around the water points. However, some of the water points in Niger were characterized by a lack of preventive maintenance and the existence of solid waste and stagnant water around them. In addition, the water users' fees (the water points in Niger were community water points) were not always collected resulting in some cases in the shortage of funds for maintenance and repairs.

Our results show that there is correlation between the five sustainability categories as they impact each other either directly or indirectly. While being the most important sustainability categories with the highest weights, the financial, social, and institutional categories have an impact on the technical and environmental categories through a cause and effect relationship. In the domain of water supply it is safe to assert that the social sustainability category has a strong correlation with the financial sustainability category. This finding highlights the social component of water supply projects as the center piece in the overall sustainability of the project because it guides the financial aspect of sustainability which relates undoubtedly to all the other factors identified as crucial to the overall sustainability of the investments made by USAID WA-WASH in Burkina Faso, Ghana, and Niger. Overall, and despite the Program's similar interventions in the three countries, the communities in Ghana were better organized than those in Burkina Faso and Niger and took good care of their water points.

Millions of dollars have been and continue to be injected in developing countries in order to help issues related to basic needs such as the provision of a safe water supply. These funds will be vain unless they are designed and accompanied by a sustainability assurance component. This is necessary to guarantee that the services provided remain operational even after the ends of the funding from international development agencies and other institutions. 
In this case study, the results showed that in general the water supply activities have a good sustainability score. While water supply proved to be highly influenced by the social aspect in/of the beneficiary communities. Taking this social component of the activities a step further, it is noted that privately managed and community managed water points were implemented. Our sustainability results were not conclusive in terms of the durability of the community managed water points versus the ones owned by the households. One would think that a privately-owned water point would be taken care of better than a community management water point. A better sense of ownership of the community water points could lead to a better organization and care of the water point. Conversely, a household owned water point because it is used less often should last longer and will be more sustainable. Thus, we cannot recommend that community managed water points should be prioritized over household managed ones. Therefore, the focus of the development efforts in the rural areas for all three countries should focus on water supply technologies especially low-cost technologies to bring more access to basic services with an emphasis on the sustainability of the built facilities/installations.

In conclusion, finally, we observed that after four years, most beneficiaries continue to use the information and skills they have acquired from the Program support through capacity building, focus group discussions, and technical assistance, and the majority of the water points in the three countries continue to be function and are serving the needs for which they were intended.

\section{ACKNOWLEDGEMENTS}

This work was funded by the people of the United States through the Agency for International Development (USAID) within the framework of the West Africa Water Supply, Sanitation, and Hygiene (USAID WA-WASH) Program. The views and opinions of the authors expressed herein do not necessarily state or reflect those of the United States Agency for International Development of the United States Government.

\section{REFERENCES}

[1] United Nations Development Program, Human Development Report, 2018. Online. http://hdr.undp.org/sites/default/files/2018_human_development_statistical_ update.pdf. Accessed on: June 2019.

[2] Joint Monitoring Program for Water Supply and Sanitation Report, 2017. https://washdata.org/data\#!/. Accessed on: Jun. 2019.

[3] Abrams, L.J., Understanding Sustainability of Local Water Services, 1998. http://wn.apc.org/afwater/sustainability.htm. Accessed on: Jun. 2018.

[4] Hodgkin, J., The sustainability of donor-assisted rural water supply projects. 1994, WASH Technical Report No. 94. http://pdf.usaid.gov/pdf_docs/PNABQ942.pdf. Accessed on: Jun. 2019.

[5] Schouten, T. \& Moriarty, P., Community Water, Community Management: From System to Service in Rural Areas, ITDG Publishing, 2003.

[6] Choguill, C.L., Ten steps to sustainable infrastructure. Habitat International, 20(3), pp. 389-404, 1996.

[7] Bhandari, B. \& Grant, M. User satisfaction and sustainability of drinking water schemes in rural communities of Nepal. Sustainability: Science, Practice and Policy, 3(1), pp. 12-20, 2007.

[8] Pushpangadan, K. \& Murugan, G., Dynamics of Rural Water Supply in Coastal Kerala: a Sustainable Development View, National Seminar on 'Crisis in Drinking Water', Gandhinagar, Gujarat, 2007. 
[9] Rietveld, L.C., Haarhoff, J. \& Jagals, P., A tool for technical assessment of rural water supply systems in South Africa. Physics and Chemistry of the Earth, 34(1-2), pp. 43-49, 2009.

[10] Lockwood, H., Scaling Up Community Management of Rural Water Supply, IRC International Water and Sanitation Centre, 2004.

[11] Kaliba, A. \& Norman, D., Assessing sustainability of community-based water utility projects in central Tanzania with the help of canonical correlation analysis. Journal of Environmental Assessment Policy Management, 6(1), pp. 73, 2004.

[12] Boulenouar, J., Schweitzer, R. \& Lockwood, H., Mapping of Sustainability Assessment Tools to Support Sustainable Water and Sanitation Service Delivery, Triple-S Working Paper 6, 2013. 